\title{
KAPOSI'S HÆMANGIOSARCOMA OF THE HEART
}

\author{
BY \\ MICHAEL GELFAND \\ From the African Hospital, Salisbury, Rhodesia
}

There are numerous reports of the frequency with which Kaposi's sarcoma is encountered in the African. It is a true but atypical sarcoma, starting as a single reddish or purplish nodule on one or both lower extremities. Further nodules form slowly and spread up the limb, while at the same time the earlier lesions tend to coalesce. The condition is generally bilateral, resulting in a stocking distribution, which later spreads to the trunk, upper limbs, or viscera. The African appears to possess a peculiar predisposition to the disease, which in Europe is frequent amongst the labouring classes in Italy, where it was originally described. Women are rarely affected. Death is invariable, but the interval between the onset of the condition and death varies. Visceral manifestations usually occur from two to five years after the onset of the disease, which generally terminates fatally in three to eight years.

Referring to the site of secondary deposits, Choisser and Ramsey (1939) include the respiratory tract, lymph nodes, stomach, intestines, liver, kidney, and bladder. In their review on the disease, they failed to find a case of cardiac or pericardial involvement, but were themselves able to record two European cases in which the lesions were primarily in the heart but not found in the skin: in both the disease ran a rapid downhill course, the patients dying of cardiac tymponade. Autopsy showed proliferative lesions, involving primarily the right atrum with spread to the myocardium, pericardium, diaphragm, and mediastinum, and isolated lesions in the liver and lungs. A closer study of reported cases revealed eight heart tumours variously diagnosed, in which they regarded the microscopical picture as identical with Kaposi's sarcoma although, as they stated in their review of cases reported as such, they had been unable to find a single instance in which the condition was primary in the heart.

The pathology of the disease is of interest. The tumour is composed of small newly formed blood vessels, with walls composed only of cells resting on a reticular base. In other places the blood sinuses are full of blood or debris. Small foci of polymorphonuclear leucocytes and lymphocytic infiltration are usually also present. As well as the blood vessels there are more solid portions of the tumour consisting of proliferative embryonic spindle cells differing in size, shape, and arrangement: some are small, others large, and all possess hyperchromatic nuclei with only an occasional mitotic figure. The structure of the tumour varies in different portions as does the pleomorphism in individual regions, but the important feature to be noticed is its vascularity.

\section{Case Report}

The patient was a well-built adult African male, aged about 38 years, who was admitted to the Salisbury Native Hospital. He complained that his feet and later his legs had begun to swell four months before and had become progressively worse until the time of his admission when it reached well up his trunk and included his arms. He had noticed too that he was short of breath on exertion, but did not experience any pain in the chest.

On examination, the patient was orthopnœic and œdematous. He was afebrile with a regular pulse and a blood pressure of $165 / 125$. The veins in the neck were full and distended but did not pulsate. The apex beat could neither be seen nor felt and the heart sounds were distant and muffled. The left base on percussion was stony dull with absent air entry. An X-ray of the chest revealed an enlarged cardiac silhouette resembling a moderately large pericardial effusion and a moderate leftsided pleural effusion. The cardiogram showed very low voltage $R$ and absent $T$ waves in the 
standard leads. The hæmoglobin was 107 per cent and blood urea $24 \mathrm{mg}$. per $100 \mathrm{ml}$. The total serum proteins were $6.5 \mathrm{~g}$. per $100 \mathrm{ml}$. and the white cell count normal. The Wassermann reaction of the blood was negative.

The legs and feet were odematous and showed no other abnormality save the skin over the extremities which was pellagroid in type. The liver was enlarged and its edge could be felt four fingers below the right costal margin, its edge and surface being smooth and hard. A moderate ascites was present.

A pericardial aspiration was performed and the clear straw-coloured fluid removed proved sterile on culture. As tuberculosis is the most common cause of pericardial effusion in the African, it was decided to institute a course of streptomycin. However, the patient failed to improve and died three weeks later.

Autopsy. At autopsy the significant changes were present in the heart which was enclosed in a clear straw-coloured pericardial effusion. On inspection the striking feature was that its whole surface (ventricles and atria) was covered in raspberry-like tumours of varying size (Fig. 1). The

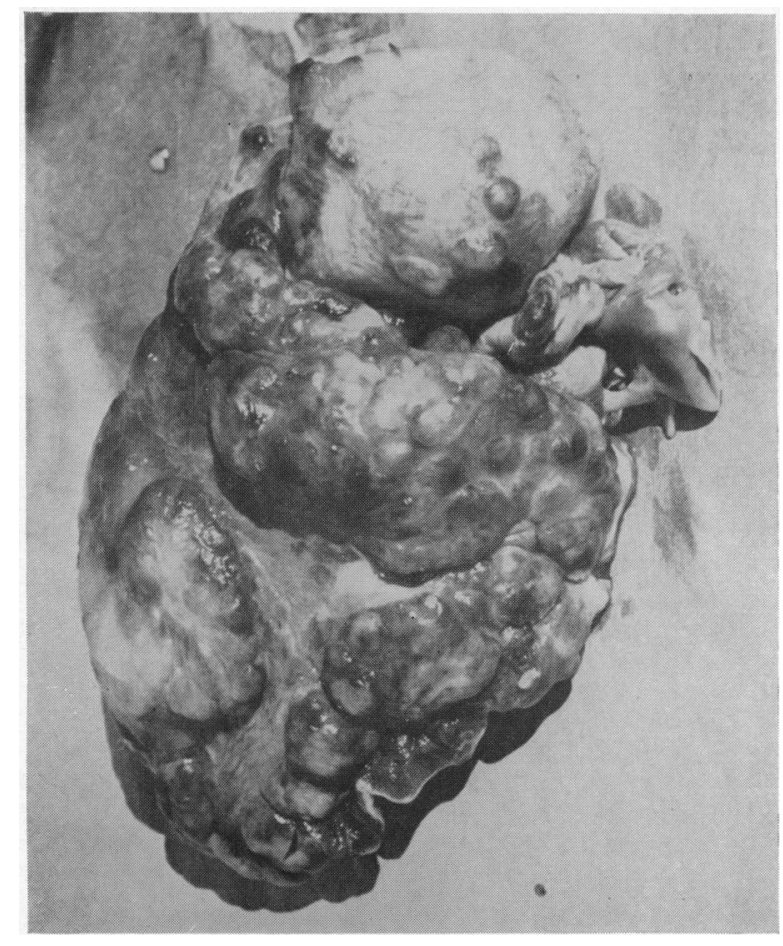

FIG. 1

tumours were irregular in shape, some measuring as much as $18 \mathrm{~mm}$. in length while others were much smaller, about $6 \mathrm{~mm}$. They were studded over the whole myocardium, equally in each chamber, and had invaded the muscle to about a quarter of its depth. None could be seen on the endocardial surfaces and the valves were normal. The lungs and pleuræ were unaffected by these tumours in spite of the effusion in the left pleural sac and no growths were found anywhere else in the body. The liver was enlarged and congested. I did not recognize the nature of the disorder. Portions of the heart and tumours were submitted to Dr. J. F. Murray of Johannesburg who identified the condition as a Kaposi hamangiosarcoma.

"The sections from the heart are most interesting. They show the presence of a Kaposi hæmangiosarcoma, a condition in which I have been interested for some years. During that time I have collected just over one hundred cases, but this is only the second in which cardiac lesions have been present." 
The histological picture varied in the different parts of tissue examined. The disordered architectural arrangement and multiplicity of cellular proliferation were striking, with vascularity the common feature. In some parts the cells were spindle-shaped with little pleomorphism and with dark-staining nuclei. Between the cellular structure lay newly formed blood vessels consisting of endothelium and resting on a reticular base. These walls were at times broken, permitting extravazation of blood and their vessels were engorged with blood cells. In many respects this tissue might be mistaken for a soft fibroma or even chronic granulation tissue.

In other parts the structure was different with more primitive cells of varying size, shape, and arrangement, and a few mitotic figures. The nuclei were larger and stained pale blue. Some of the cells were arranged to form new blood vessels, sometimes in double layers and sometimes lining only a single layer. Sheets of these cells invaded the myocardium often at some distance from the main site of the tumour.

\section{Comments}

There were two points of special interest in this case. First, the clinical picture was that of a pericardial effusion believed to be tuberculous. Secondly, no lesions of Kaposi's tumour were present in the skin or internal organs other than the heart. Although Kaposi's tumour, as a cause of heart failure, is uncommon, it should be remembered as a possibility in a male African when the ætiology is not immediately obvious.

I wish to thank Dr. R. M. Morris, Secretary for Health, Rhodesia and Nyasaland for his permission to publish this paper.

\section{References}

Choisser, R. M., and Ramsey, E. M. (1940). Southern Med., 33, 392.

(1939). Amer. J. Path., 15, 155. 